\title{
USO DE BIOMASSA DE MICROALGA PARA BIOSSORÇÃO DE LANTANÍDEOS
}

\author{
G. P. HEIDELMANN, T. M. ROLDÃO, S. G. EGLER, M. NASCIMENTO, E. C. GIESE* \\ Centro de Tecnologia Mineral (CETEM), Rio de Janeiro, Brasil \\ egiese@cetem.gov.br
}

Submetido 17/10/2017 - Aceito 27/11/2017

DOI: $10.15628 /$ holos.2017.6436

\section{RESUMO}

As algas e microalgas vêm sendo estudadas quanto à sua habilidade em biossorver elementos de terras-raras através da troca iônica com grupos ligantes presentes na superfície dos revestimentos celulares. Assim, o presente trabalho buscou avaliar a capacidade da biomassa liofilizada da microalga Chlorella vulgaris (Chlorophyta) na biossorção do lantânio-La, visando seu uso na separação de terras-raras. Os ensaios de biossorção de La foram conduzidos em batelada, onde suas concentrações residuais foram determinadas com o uso de ICP-OES. Constatou-se que a biossorção de espécies iônicas de La foi dependente do $\mathrm{pH}$ inicial de cada ensaio. A capacidade de biossorção foi maior em
\end{abstract}

valores de $\mathrm{pH}$ mais baixos. Uma vez que o ponto de carga zero foi determinado em valor de $\mathrm{pH} 5,59$, podese concluir que espécies aniônicas de La estejam presentes em solução. Os valores de $\mathrm{q}_{\text {máx }}$ revelam a capacidade de biossorção de espécies iônicas de La pela biomassa de $C$. vulgaris, a qual apresentou um valor de $1,11 \mathrm{mg} / \mathrm{g}(0,8 \mathrm{mmol} / \mathrm{g})$. As isotermas demonstraram que, nas condições experimentais avaliadas, a biossorção de La ocorre de acordo com o modelo proposto por Freundlich, em um processo de adsorção reversível em sistema heterogêneo.

PALAVRAS-CHAVE: Chlorella vulgaris, biossorção, terras-raras, lantânio

\section{MICROALGAE BIOMASS USE FOR LANTANIDES BIOSORPTION}

\begin{abstract}
Some algae and microalgae have been studied for their ability to biosorb rare earth elements through ion exchange with binder groups present on the cellular surface coatings. Thus, the present work evaluated the capacity of lyophilized biomass of the microalgae Chlorella vulgaris (Chlorophyta) in lanthanum-La biosorption, aiming its use in the separation of rare earths. The biosorption assays were conducted in batch and their residual concentrations were determined using ICP-OES. It was found that the biosorption of ionic species depended on the initial $\mathrm{pH}$ of each assay. The
\end{abstract}

KEYWORDS: Chlorella vulgaris, biosorption, rare earth, lanthanum 


\section{INTRODUÇÃO}

As terras-raras possuem inúmeras aplicações industriais, principalmente em tecnologias de ponta, destacando-se laseres, fósforos, lentes, super-imãs, vidros e cerâmicas, micro-ondas, sensores, corantes, revestimentos, condutores eletrônicos, catalisadores de craqueamento e de oxidação (Silva Júnior \& Campos, 2016, Souza Filho \& Serra, 2014).

O seu alto valor de mercado é decorrente do alto custo dos processos de extração, separação e recuperação, além da dificuldade de obtenção de compostos de alta pureza. Isto ocorre devido à natureza do estado de oxidação 3+ de alta estabilidade dos elementos de terrasraras, resultando em propriedades químicas e físicas muito similares entre eles (Ferreira \& Nascimento, 2013).

Os processos convencionais de separação de terras-raras incluem os processos de extração líquido-líquido (solventes) ou sólido-líquido (troca iônica) (Vera, 2015). A troca-iônica pode ser utilizada na remoção de impurezas metálicas de plantas de processos hidrometalúrgicos de terras-raras, urânio e metais do grupo da platina. Este processo é adequado para processos de purificação onde o produto final de maior pureza apresenta alto valor agregado, assim como para a recuperação de produtos de valor de interesse os quais se encontram em concentrações mais baixas em solução e podem ser recuperados em processos de adsorção (Streat, 1986).

A biossorção é um processo alternativo de troca-iônica que vem sendo testado na recuperação de elementos de terras-raras a partir de soluções sintéticas. A biossorção consiste em um processo de remoção de íons através de interações eletrostáticas, formação de complexos, troca iônica e reações de precipitação que podem ocorrer na superfície celular (Giese, Magalhães e Egler, 2016). O interesse no estudo de processos biotecnológicos na recuperação e separação de terras-raras vem da necessidade de se adaptar os processos hidrometalúrgicos buscando uma maior eficiência do uso dos recursos naturais com processos menos onerosos e de menor impacto ambiental.

As algas têm sido estudadas quanto a sua capacidade de biossorção de terras-raras. Elas possuem um revestimento celular constituído de polissacarídeos e proteínas, os quais apresentam grupos carboxílicos aniônicos, grupos sulfatos e grupos fosfatos que podem se ligar passivamente a estes elementos. Neste caso ainda, para ocorrer a ligação terra-rara/alga é necessário o deslocamento de cátions como, por exemplo, os íons $\mathrm{Ca}^{2+}$ (Diniz \& Voleski, 2005, Klimmek, Stan, Wilke, Bunke e Buchholz, 2001).

Tendo em vista a possibilidade da aplicação dos biossorventes na recuperação de terrasraras em soluções diluídas, o presente trabalho trata de um estudo preliminar sobre o uso da biomassa liofilizada da microalga Chlorella vulgaris (Chlorophyta) na biossorção do lantânio-La, visando seu uso na recuperação deste elemento após etapas anteriores de extração.

\section{ASPECTOS TEÓRICOS}

As terras-raras consistem dos elementos da tabela periódica localizados na série dos lantanídeos (número atômico 57 a 71), incluindo o ítrio (número atômico 39) e o escândio (número atômico 21), os quais apresentam propriedades químicas e físicas muito semelhantes 
(Ferreira \& Nascimento, 2013). O alto valor de mercado de terras-raras é decorrente do alto custo dos processos de separação e purificação e da grande dificuldade de separação dos elementos e da obtenção de compostos de alta pureza. Estes processos envolvem várias etapas de extração por solventes e/ou resinas de troca-iônica e poucos países dominam a tecnologia de separação de terras-raras, a qual é de grande importância para as políticas econômicas visto que os produtos relacionados a essas commodities têm alto valor agregado (Giese, 2017, Vera, 2015).

A extração de terras-raras a partir de seus minérios de origemé realizada por processos físicos de separação granulométrica, flotação e separação magnética. Após as etapas de processamento mineral, as amostras são então separadas através de métodos baseados na extração por solventes e troca iônica. Na troca iônica, a intensidade de atração dos lantanídeos pelos sítios ativos de carga negativa da resina dependerá do raio iônico hidratado e quanto menor for este tamanho, maior será a interação (Zinner, 1982). A troca iônica é preferencial nas etapas finais de polimento dos produtos obtidos nas etapas anteriores, devido à baixa concentração de terras-raras a serem retiradas da solução (Texier, Andrès, Faur-Brasquet e Le Cloireç, 2002).

Neste contexto, a biossorção tem sido descrita na literatura científica como uma ferramenta potencial de troca iônica para a recuperação e separação de elementos de terrasraras (Andrès, Thouand, Boualam e Mergeay, 2000, Das \& Das, 2013, Heilmann, Jurkowski, Buchholz, Brueck e Becker, 2015, Gad, 2016, Kücüker, Wieczorek, Kuchta e Copty, 2017, Takahashi, Yamamoto, Yamamoto e Tanaka, 2010). A biossorção promove a remoção de íons por sua ligação passiva com sítios ativos de biomassas vivas ou mortas em soluções aquosas. Neste processo, a interação íon-biomassa é baseada nas propriedades químicas dos revestimentos celulares do biossorvente, como a presença de grupos carboxílicos e fosfóricos, e não em sua atividade biológica (Giese, Magalhães e Egler, 2016).

O uso da biossorção dentro de um processo industrial é incentivado pelo menor custo de operação e também do material biossorvente. Dentre outras vantagens destacam-se a alta eficiência na remoção do elemento de interesse a partir de soluções contendo baixas concentrações do mesmo, a fácil regeneração do material biossorvente e o potencial de recuperação dos elementos biossorvidos, além da minimização de resíduos e rápida cinética de adsorção e dessorção (Olukanni, Agunwamba e Ugwu, 2014, Zimmermann \& Wolf, 2002).

Dentre as algas estudadas, o grupo mais utilizado por variedade de terras-raras é o das macroalgas marinhas marrons, devido sua constituição bioquímica básica formada por concentrações elevadas de alginato e grupos carboxílicos em abundância, ambos capazes de capturar cátions presentes em solução (Davis, Volesky e Mucci, 2003). No processo de biossorção, para que ocorra a interação terra-rara/alga é ainda necessário o deslocamento de cátions preexistentes, sendo o $\mathrm{Ca}^{2+}$ o principal deles. Diniz e Voleski (2005) demonstraram que a troca entre íons de $\mathrm{Ca}^{2+}$ para a ligação com $\mathrm{La}^{3+}, \mathrm{Eu}^{3+} \mathrm{e} \mathrm{Yb}^{3+}$ em Sargassum polycystum ocorre na proporção 1:1, ou seja, a mesma concentração de $\mathrm{Ca}^{2+}$ liberada em solução correspondeu à mesma concentração de terras-raras biossorvidas pela alga.

Por outro lado, as microalgas verdes também têm sido avaliadas como biossorventes de terras-raras. A microalga verde de água doce Chlamydomonas reinharditii, por exemplo, foi descrita por biossorver $1,03 \mathrm{mmol}$ La/g em 5h (Birungi \& Chirwa, 2014). O mesmo pode ser observado para neodímio $(\mathrm{Nd})$, onde estudos demonstraram que as microalgas verdes de água 
doce Acanthorhodeus gracilis e Monoraphidium sp. biossorveram 0,98 mmol Nd/g e 0,94 mmol $\mathrm{Nd} / \mathrm{g}$, respectivamente, para $2 \mathrm{~h}$ de exposição (Palmieri, Volesky e Garcia, 2000). Testes em coluna com biomassa imobilizada da microalga Ankistrodesmus sp. apresentaram $80 \%$ de eficiência na biossorção de lantânio sem atingir a saturação em 8 horas de processo contínuo (Corrêa, Luna e Costa, 2017).

\section{MATERIAIS E MÉTODOS}

A microalga clorofícea Chlorella vulgaris (Chlorophyta) foi cultivada em meio LC-Oligo (ABNT, 2011) sob iluminação constante com temperatura controlada, sendo repicada semanalmente. A biomassa resultante da centrifugação do cultivo líquido (4500 rpm/10 min) foi ressuspendida em água ultrapura e congelada a $-4^{\circ} \mathrm{C}$. Posteriormente, a biomassa foi liofilizada e utilizada como material biossorvente.

A metodologia de determinação do ponto de carga zero (PCZ) consistiu em pesar massas de $50 \mathrm{mg}$ da biomassa de $C$. vulgaris e adicionar a $50 \mathrm{~mL}$ de soluções aquosas com $\mathrm{pH}$ inicial de 1,$0 ; 2,0 ; 3,0 ; 4,0 ; 5,0 ; 6,0 ; 7,0 ; 8,0 ; 9,0 ; 10,0$ e 11,0 ajustados com solução de $\mathrm{NaOH}$ ou $\mathrm{HCl}$ 0,1 M. Após o período de 24 horas sob agitação constante de $100 \mathrm{rpm}$ a $30^{\circ} \mathrm{C}$, foram determinados os valores de $\mathrm{pH}$ final com a ajuda de um pHmetro (marca Digimed), previamente calibrado com soluções tampão de $\mathrm{pH}$ 4,0 e 7,0.

Os experimentos de biossorção em batelada foram realizados em Erlenmeyers de $250 \mathrm{~mL}$ contendo aproximadamente $50 \mathrm{mg}$ de material biossorvente e $50 \mathrm{~mL}$ de solução de $\mathrm{LaNO}_{3}$ em diferentes concentrações. Os frascos foram agitados em shaker a $100 \mathrm{rpm}$ e $30^{\circ} \mathrm{C}$. Após 1 hora de contato, a mistura foi centrifugada para a separação do material biossorvente. $\mathrm{O}$ pH inicial da solução ótimo para os ensaios de biossorção foi determinado através de ensaios em diferentes valores de $\mathrm{pH}(3,5$ e 7) em concentração inicial de La de $15 \mathrm{mg} / \mathrm{L}$. Para a construção dos isotermas de adsorção, as seguintes concentrações de La foram avaliadas: 15, 30, 50, 75 e 100 $\mathrm{mg} / \mathrm{L}$. A determinação da concentração final de La em solução foi realizada utilizando espectrometria de emissão óptica por plasma acoplado indutivamente (ICP-OES, marca Horiba, modelo ULTIMA 2).

\section{RESULTADOS E DISCUSSÃO}

\subsection{Efeito de pH e ponto de carga zero (PCZ)}

Os processos de adsorção são fortemente dependentes do $\mathrm{pH}$, uma vez que o mesmo afeta o grau de ionização e especiação dos metais em solução, além de afetar também a carga superficial dos sítios ativos do material biossorvente (Andrès, Thouand, Boualam e Mergeay, 2000). A tendência de uma superfície apresentar carga positiva ou negativa em função do pH pode ser avaliada através da determinação do ponto de carga zero (PCZ).

O PCZ, ou ponto isoelétrico, é definido como o pH em que a superfície do biossorvente possui carga neutra. De maneira geral, a adsorção de cátions será favorecida em valores de $\mathrm{pH}$ maiores que o PCZ (carga superficial negativa), enquanto a adsorção de ânions será favorecida abaixo do PCZ (carga superficial positiva) (Milonjić, Kopecni e llić, 1983). 
O PCZ para a biomassa de $C$. vulgaris resultou em $\mathrm{pH}$ de 5,59 , como pode ser observado na Figura 1.

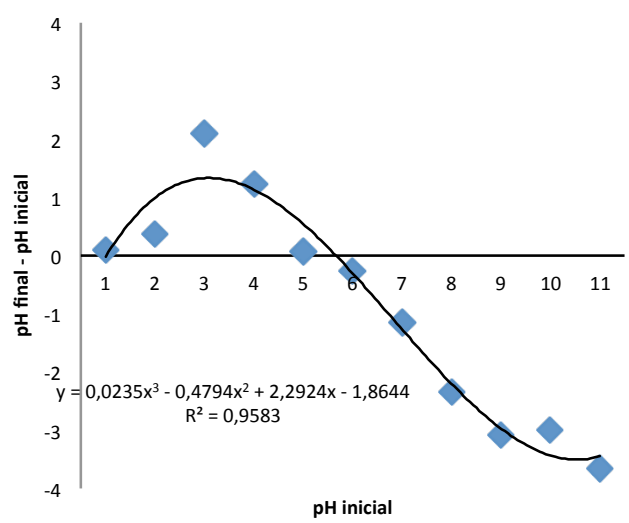

Figura 1: Curva para determinação do ponto de carga zero (PCZ) para a biomassa liofilizada de Chlorella vulgaris.

Através da análise do gráfico polinomial, é possível estimar o aumento na capacidade de retenção de ânions, com aumento do $\mathrm{pHi}$ até próximo de 3,0. Após este valor de $\mathrm{pH}$, a retenção diminui gradativamente até que em pHi próximo ao $\mathrm{PCZ}, 5,59$, as cargas positivas e negativas se equivalem, etapa esta em que a curva intercepta o pH final $-\mathrm{pH}$ inicial $=0$. Após $\circ \mathrm{PCZ}$, predomina a atração dos cátions pela superfície do biossorvente.

De maneira geral, o PCZ descrito para diferentes espécies de algas marinhas é maior que o valor determinado no presente trabalho para a C. vulgaris. O PCZ para as algas Spirulina sp. e Scenedesmus abundans, por exemplo, foi determinado em 8,5 e 7,5, respectivamente. Sabe-se que no caso da carga superficial da biomassa de algas, a mesma depende do estado de protonação-desprotonação dos vários grupos funcionais, isto é, carboxila, hidroxila, amida e amina, os quais podem variar de acordo com o gênero e espécie estudados (Mishra \& Mukherji, 2012).

Ensaios de biossorção de La em diferentes valores de $\mathrm{pH}$ inicial foram realizados com o objetivo de se avaliar o comportamento da biomassa de $C$. vulgaris como material biossorvente. Os dados da biossorção de La em função do pH estão apresentados na Figura 2.

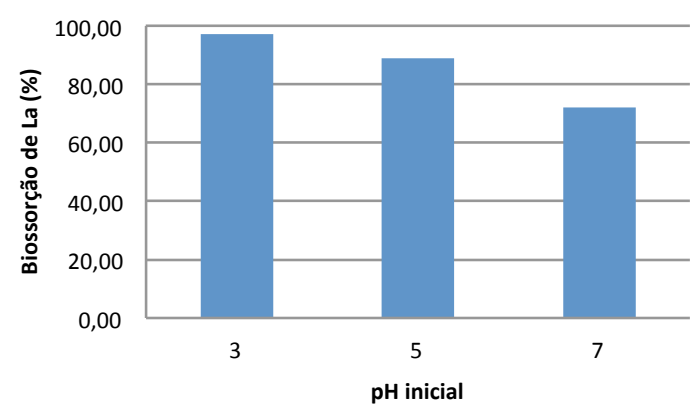

Figura 2: Efeito do pH na biossorção de espécies de La utilizando biomassa liofilizada de Chlorella vulgaris, $\mathrm{C}_{\text {inicial }}=$ $15 \mathrm{mg} / \mathrm{L}, \mathrm{C}_{\text {biomassa }}=1 \mathrm{~g} / \mathrm{L}$, tempo de contato $=1$ hora. 
Podemos observar que as porcentagens de biossorção de La pela biomassa de $C$. vulgaris diminuíram com o aumento dos valores de $\mathrm{pH}$ em cerca de 1,3 vezes, de 97,3\% em pH 3,0 para $72,2 \%$ em $\mathrm{pH} 7,0$.

De acordo com os resultados anteriores, em valores de $\mathrm{pH}$ menores que 5,59 (PCZ), a superfície celular da biomassa de $C$. vulgaris estaria carregada positivamente e um grande número de ânions poderia ser adsorvido para balancear as cargas positivas. A maior porcentagem de biossorção de espécies iônicas de La em valores de pH menores que o PCZ neste trabalho, pode ser explicada pela existência de complexos aniônicos de terras-raras em solução, como o $\mathrm{La}\left(\mathrm{NO}_{3}\right)^{4}$. Esta espécie pode estar presente em solução uma vez que o óxido de lantânio utilizado nos experimentos realizados foi solubilizadoem ácido nítrico concentrado.

Com a diminuição do $\mathrm{pH}$, grupos funcionais tais como amina e carbonila favorecem superfícies celulares carregadas positivamente que, consequentemente, podem contribuir para a biossorção de metais e terras-raras presentes como espécies aniônicas (Kuyucak \& Volesky, 1988). Além disso, podem existir outras interações mais importantes que as forças eletrostáticas, diminuindo o efeito da carga superficial.

\subsection{Isotermas de adsorção}

A avaliação quantitativa da biossorção de La pela biomassa liofilizada de $C$. vulgaris foi realizada através de experimentos em diferentes concentrações iniciais de La como descrito na Tabela 1. Pode-se observar que as quantidades de La biossorvidos foram crescentes até concentrações de equilíbrio em torno de $69,8 \mathrm{mg} / \mathrm{L}$ (0,50 mmol/L) e 91,1 mg/L (0,66 mmol/L). As porcentagens de biossorção diminuíram em função do aumento da concentração de La, o que já era esperado devido à saturação dos grupos ativos presentes no material biossorvente.

Tabela 1: Capacidades de biossorção e \% de diferentes concentrações iniciais de La ( $\left.\mathrm{C}_{\text {inicial }}\right)$ para a biomassa liofilizada da microalga Chlorella vulgaris. $\mathrm{pH}$ inicial = 3,0.

\begin{tabular}{c|c|c}
\hline $\begin{array}{c}\mathrm{C}_{\text {inicial }} \\
(\mathrm{mg} / \mathrm{L})\end{array}$ & $\begin{array}{c}\mathrm{q} \\
(\mathrm{mg} / \mathrm{g})\end{array}$ & $\begin{array}{c}\text { Biossorção } \\
(\%)\end{array}$ \\
\hline 10,1 & 0,45 & 92,38 \\
12,3 & 0,58 & 94,96 \\
41,5 & 0,86 & 43,25 \\
69,8 & 1,26 & 44,84 \\
91,1 & 1,37 & 31,67 \\
\hline
\end{tabular}

Os parâmetros obtidos pelas isotermas de adsorção previstas pelos modelos de Langmuir e Freundlich, com o objetivo de descrever o sistema de biossorção, encontram-se apresentados na Tabela 2. Os valores de $q_{\max }$ revelam a capacidade de biossorção de espécies iônicas de La pela biomassa de C. vulgaris, a qual apresentou um valor de $1,11 \mathrm{mg} / \mathrm{g}(0,8 \mathrm{mmol} / \mathrm{g})$. 
Tabela 2: Constantes de adsorção do La para a biomassa liofilizada da microalga Chlorella vulgaris.

\begin{tabular}{c|c|c|c|c|c|c|c}
\hline \multirow{2}{*}{ La } & \multicolumn{3}{|c|}{ Langmuir } & \multicolumn{4}{c}{ Freundlich } \\
\cline { 2 - 9 } & $\mathrm{q}_{\max }(\mathrm{mg} / \mathrm{g})$ & $K_{\mathrm{L}}(\mathrm{L} / \mathrm{mg})$ & $\mathrm{R}^{2}$ & $k_{F}(\mathrm{~L} / \mathrm{mg})$ & $n$ & $1 / n$ & $\mathrm{R}^{2}$ \\
\cline { 2 - 9 } & 1,11 & 1,25 & 0,776 & 0,54 & 4,84 & 0,21 & 0,899 \\
\hline
\end{tabular}

O valor de $q_{\text {máx }}$ obtido foi similar ao encontrado na literatura para os estudos de biossorção de terras-raras por algas verdes e marrons. Palmieri et al. (2002), por exemplo, observaram q $q_{\text {máx }}$ de 0,73 mmol/g para a biossorção de La por Sargassum sp. Oliveira et al. (2011), por sua vez, observaram valores de $q_{\text {máx }}$ de 0,65 e 0,71 mmol/g para a biossorção de samário $(\mathrm{Sm})$ e praseodímio $(\mathrm{Pr})$, respectivamente, pela mesma espécie de alga marrom. O qmáx de 1,03 $\mathrm{mmol} / \mathrm{g}$ foi observado para a biossorção de La pela alga verde Chlamydomonas reinhardtii (Birungi \& Chirwa, 2014). Por outro lado, valores elevados de $q_{\text {máx }}$ foram obtidos para a biossorção de Nd pela C. vulgaris, de 123,82 mg/g em pH 4,0 e 157,21 mg/g em pH 5,0 (Kücüker, Nadal e Kuchta, 2016).

Kücüker et al. (2017) demonstraram que para a biossorção de $\mathrm{Nd}$ pela biomassa de $C$. vulgaris, a análise dos dados ótimos de adsorção se ajustou melhor $\left(R^{2}=0,98\right)$ ao modelo de Langmuir, com $q_{\text {máx }}$ de 188,68 mg Nd/g e $K_{\mathrm{L}}$ de 0,029 L/mg. Neste experimento, a biomassa da microalga foi tratada através de secagem à $90^{\circ} \mathrm{C}$ durante $24 \mathrm{~h}$ antes de ser utilizada como biossorvente e a solução contendo $\mathrm{Nd}$ consistiu na lixívia ácida proveniente de imãs $\mathrm{Nd}-\mathrm{Fe}-\mathrm{B}$ cominuídos.

Em outro estudo, quando comparada com outras microalgas, a biossorção de La pela biomassa de C. vulgaris também se ajustou melhor ao modelo de Langmuir. A microalga Desmodesmus multivariabilis foi a espécie que apresentou maior $q_{\text {máx }}(100 \mathrm{mg} \mathrm{La} / \mathrm{g}$ ) e maior afinidade pelo La ( $\left.K_{L}=4,55 \mathrm{~L} / \mathrm{g}\right)$ (Birungi \& Chirwa, 2014).

No presente trabalho, a isoterma de Freundlich foi a que melhor se ajustou aos dados experimentais $\left(R_{2}=0,89\right)$, indicando que o modelo ajusta adequadamente os dados. Ou seja, nas condições experimentais estudadas, o La pode ser adsorvido de acordo com as aproximações deste modelo, que sugere um sistema heterogêneo e um processo de adsorção reversível. 0 prevalecimento do ajuste pela isoterma de Freundlich pode indicar a tendência de adsorção de La em baixas concentrações, enquanto que a análise do parâmetro $1 / n$ igual a 0,21 indica que a biossorção estudada é um processo favorável (Boniolo, Yamaura e Monteiro, 2010).

Deve-se levar em consideração ainda que a biossorção de espécies de La possa envolver diferentes mecanismos, como troca-iônica, microprecipitação, complexação/quelação, atração eletrostática, entre outros. Desta maneira, os ajustes dos dados de biossorção aos modelos de isoterma podem variar de acordo com as condições experimentais. Imagens de microscopia eletrônica de transmissão da parede celular da bactéria Pseudomonas sp., por exemplo, demonstraram a presença de acúmulo de La em depósitos granulares na periferia celular e no citoplasma. As análises de difração de raios- $X$ confirmaram a presença de cristais de $\mathrm{LaPO}_{4}$ na biomassa bacteriana após o tempo de contato com solução de La (Kazy, Das \& Sar, 2006).

O valor de $n$ encontrado, relativo à distribuição das espécies iônicas de La ligadas aos sítios ativos da superfície celular de C. vulgaris, foi igual a 4,84. Uma adsorção favorável apresenta valores para a constante $n$ entre 1 e 10, sendo que valores mais elevados indicam uma 
maior interação entre o material biossorvente e o soluto avaliado (Loukidou, Zouboulis, Karapantsios e Matis, 2004). Desta maneira, os resultados indicaram que as espécies iônicas de La possuem grande afinidade pela biomassa liofilizada de $C$. vulgaris e que o processo de biossorção é favorável.

\section{CONCLUSÕES}

Os experimentos realizados demonstraram a capacidade de biossorção de espécies iônicas de La pela biomassa liofilizada da microalga Chlorella vulgaris, a qual se ajustou melhor ao modelo proposto por Freundlich, não estando necessariamente restrita à formação de monocamadas. Os resultados também demonstraram que a eficiência do processo de biossorção depende do pH da solução aquosa e que devem ser também consideradas as especiações dos elementos em solução.

\section{AGRADECIMENTOS}

À FAPERJ e CNPq pelo apoio à realização do projeto. GP Heidelmann e TM Roldão agradecem aos programas $\mathrm{PIBIC/CNPq/CETEM} \mathrm{e} \mathrm{PCI} / \mathrm{CNPq} / \mathrm{CETEM}$, respectivamente, pelas bolsas concedidas.

\section{REFERÊNCIAS}

ABNT (Associação Brasileira de Normas Técnicas) NBR 12648. Ecotoxicologia aquática Toxicidade crônica - Método de ensaio com algas (Chlorophyceae). Rio de Janeiro: ABNT 2011. $24 \mathrm{p}$.

Andrès, Y., Thouand, G., Boualam, M., \& Mergeay, M. (2000). Factors influencing the biosorption of gadolinium by micro-organisms and its mobilisation from sand. Applied Microbiology and Biotechnology, 54, 262-267.

Birungi, Z. S., \& Chirwa, E. M. N. (2013). Phytoremediation of lanthanum using algae from eutrophic freshwater sources. Proceedings of the Water Environment Federation, 19, 357366.

Birungi, Z. S., \& Chirwa, E. M. N. (2014). The kinetics of uptake and recovery of lanthanum using freshwater algae as biosorbents: Comparative analysis. BioresourceTechnology, 160(1), 4351.

Boniolo, M. R., Yamaura, M., \& Monteiro, R. A. (2010). Biomassa residual para remoção de íons uranilo. Química Nova, 33, 547-551.

Corrêa, F. N., Luna, A. S., \& Costa, A. C. A. (2017). Kinetics and equilibrium of lanthanum biosorption by free and immobilized microalgal cells. Adsorption Science \& Technology, 35, 137-152.

Das, N., \& Das, D. (2013). Recovery of rare earth metals through biosorption: An overview. Journal of Rare Earths, 31(10), 933-943. 
Davis, T. A., Volesky, B., \& Mucci, A. (2003). A review of the biochemistry of heavy metal biosorption by brown algae. Water Research, 37, 4311-4330.

Diniz, V., \& Volesky, B. (2005). Biosorption of La, Eu and Yb using Sargassum biomass. Water Research, 39, 239-247.

Ferreira, F. A., \& Nascimento, M. (2013). Terras Raras: Aplicações atuais e reciclagem. Série Tecnologia Mineral, 91. CETEM/MCTIC, 72p.

Gad, N. S. (2016). Biosorption of rare earth elements using biomass of Sargassum on El-Atshan Trachytic sill, Central Eastern Desert, Egypt. Egyptian Journal of Petroleum, 25, 445-451.

Giese, E. C., Magalhães, D. P., \& Egler, S. G. (2016). Biossorção de elementos de terras-raras. Série Tecnologia Mineral, 90. CETEM/MCTIC, 75p.

Giese, E. C. (2017). Tendências européias para o uso dos recursos de terras-raras. Série Estudos e Documentos, 93. CETEM/MCTIC, 30p.

Heilmann, M., Jurkowski, W., Buchholz, R., Brueck, T., \& Becker, A. M. (2015). Biosorption of neodymium by selected photoautotrophic and heterotrophic species. Chemical Engineering \& Process Technology, 6, 1000241.

Kazy, S. K., Das, S. K., \& Sar, P. (2006). Lanthanum biosorption by a Pseudomonas sp.: equilibrium studies and chemical characterization. Journal of Industrial Microbiology and Biotechnology, 33(9), 773-783.

Klimmek, S., Stan, H. J., Wilke, A., Bunke, G., \& Buchholz, R. (2001). Comparative analysis of the biosorption of cadmium, lead, nickel, and zinc by algae. Environmental Science and Technology, 35(21), 4283-4288.

Kücüker, M. A., Nadal, J. B., \& Kuchta, K. (2016). Comparison between batch and continuous reactor systems for biosorption of neodymium $(\mathrm{Nd})$ using microalgae. International Journal of Plant, Animal and Environmental Sciences, 6(3), 197-203.

Kücüker, M. A., Wieczorek, N., Kuchta, K., \& Copty, N. K. (2017). Biosorption of neodymium on Chlorella vulgaris in aqueous solution obtained from hard disk drive magnets. PLOS ONE, 12(4): e0175255. https://doi.org/10.1371/journal.pone.0175255

Kuyucak, N., \& Volesky, B. (1988).Biosorbents for recovery of metals from industrial solutions. Biotechnology Letters, 10, 137-142.

Loukidou, M. X., Zouboulis, A. I., Karapantsios, T. D., \& Matis, K. A. (2004).Equilibrium and kinetic modeling of chromium (VI) biosorption by Aeromonas caviae. Colloids and Surfaces, 242, 93104.

Milonjić, S. K., Kopečni, M. M., \& Ilić, Z. E. (1983). The point of zero charge and adsorption properties of natural magnetite. Journal of Radioanalytical Chemistry, 78, 15-24.

Mishra, P. K., \& Mukherji, S. (2012). Biosorption of diesel and lubricating oil on algal biomass. 3 Biotech, 2, 301-310.

Oliveira, R. C., Jouannin, C., Guibal, E., \& Garcia Jr., O. (2011). Samarium (III) and praseodymium (III) biosorption on Sargassum sp.: batch study. Process Biochemistry, 46, 736-744. 
Olukanni, D. O., Agunwamba, J. C., \& Ugwu, E. I. (2014). Biosorption of heavy metals in industrial wastewater using microorganisms (Pseudomonas aeruginosa). American Journal of Scientific and Industrial Research, 5, 81-87.

Palmieri, M. C., Volesky, B., \& Garcia Jr., O. (2002). Biosorption of lanthanum using Sargassum fluitans in batch system. Hydrometallurgy, 67, 31-36.

Silva Júnior, A. F., \& Campos, M. F. (2016). Relevância das terras raras para o setor energético. HOLOS, 1, 350-364.

Souza Filho, P. C., \& Serra, O. A. (2014). Terras raras no Brasil: histórico, produção e perspectivas. Química Nova, 37, 753-760.

Streat, M. (1986) Applications of Ion Exchange in Hydrometallurgy. In: Rodrigues, A. E. (eds) Ion Exchange: Science and Technology. NATO ASI Series (E: Applied Sciences), vol 107. Springer, Dordrecht.

Takahashi, Y., Yamamoto, M., Yamamoto, Y., \& Tanaka, K. (2010). EXAFS study on the cause of enrichment of heavy REEs on bacterial cell surfaces. Geochimica et Cosmochimica Acta, 74, 5443-5462.

Texier, A. C., Andrès, Y., Faur-Brasquet, C., \& Le Cloireç, P. (2002). Fixed-bed study for lanthanide (La, Eu, Yb) ions removal from aqueous solutions by immobilized Pseudonomas aeruginosa: experimental data and modelization. Chemosphere, 47, 333-342.

Vera, Y.M. (2015). Separação de terras raras a partir da extração por solvente: revisão sobre o uso dos extratantes ácidos organofosforados. Série Tecnologia Mineral, 94. CETEM/MCTIC, $59 p$.

Zimmermann, M., \& Wolf, K. (2002). Biosorption of metals. In: Esser, K.\& Bennett, J. W. (Orgs). The Mycota: A comprehensive treatise on fungi as experimental systems for basic and applied research. Heidelberg, Germany. Springer-Verlag, p. 355-366.

Zinner, L. B. (1982). Produção e aplicações das terras-raras. Um campo pouco explorado no Brasil. Anais do VI Simpósio Anual da ACIESP. 